\title{
Nutrition and Growth
}

Mehdi Abbasi

\section{Source}

Mehdi Abbasi. (2014). Neurofibromas Or Any Other Tumors The 2014 NF-Conference

According to the general law of nutrition and growth, Nutrition could be divided into two categories: 1) healthy nutrition and 2) unhealthy nutrition. Healthy nutrition and sufficient nutrients cause natural and healthy growth while unhealthy nutrition and gluttony cause unnatural and unhealthy growth.

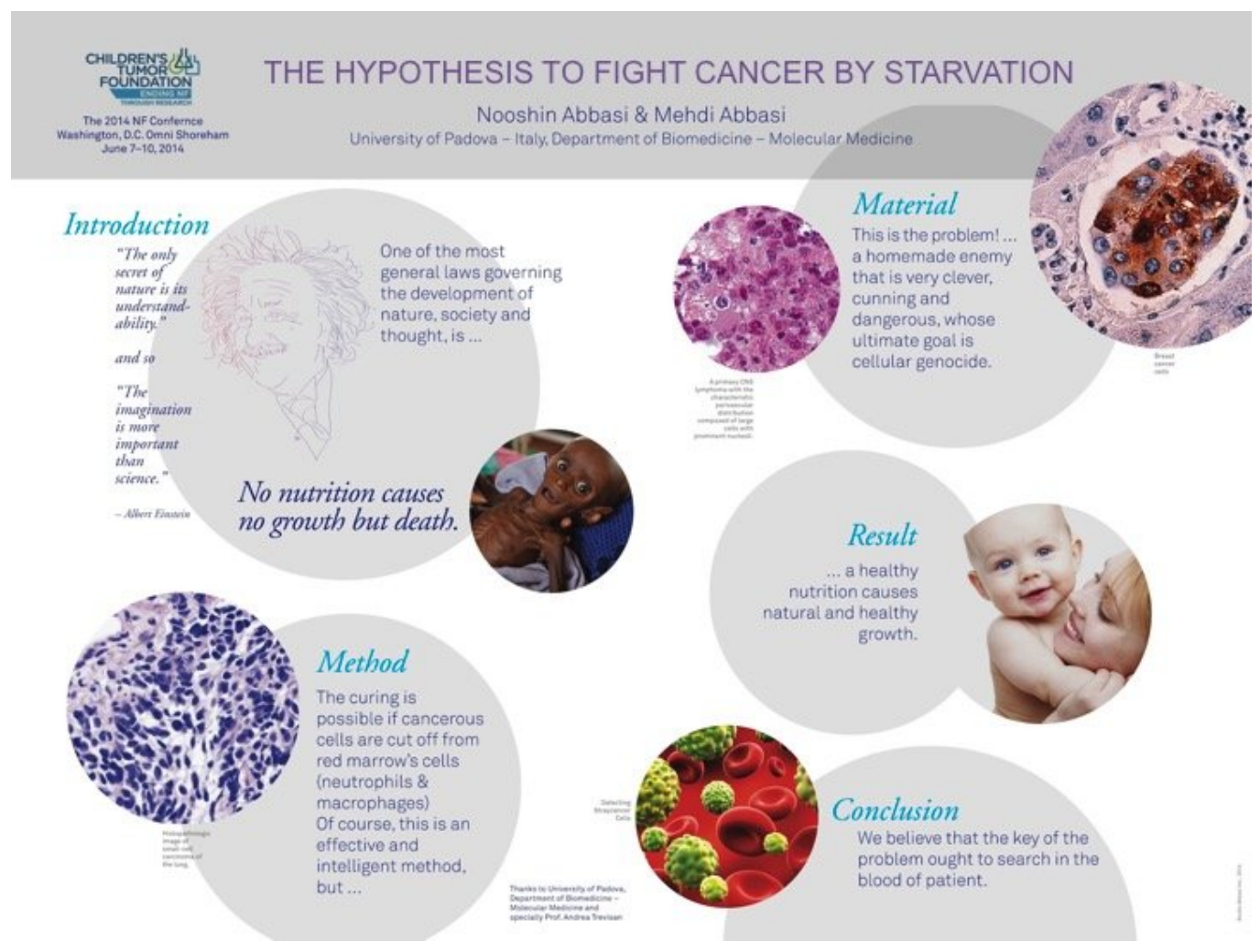

